\title{
Como lidar com clientes difíceis. Uma releitura do trabalho do Dr. Rick Brinkman e Dr. Rick Kirschner voltado para o atendimento ao cliente
}

\author{
Guilherme Dias \& Marcos Isern \\ UNIARA
}

E-mail: gui.gdelive.com/monteararaquaraeterra.com.br

\begin{abstract}
Resumo
Indiferente do meio de compra, seja ele

tudos destes autores para entender mefísico ou não, enfrenta-se sérios problemas com relação a clientes com comportamentos difíceis, principalmente quando não conseguem satisfazer suas necessidades e intenções. Dr. Rick Brinkman e Dr. Rick Kirschner estudaram o comportamento humano para entender melhor comportamentos difíceis e conseguiram classificar dez comportamentos difíceis de lidar baseados em suas intenções e o foco em que cada um deles direciona. O objetivo desse trabalho é utilizar os eslhor o comportamento do nosso cliente quando suas necessidades não são satisfeitas, gerando assim desconforto e comportamentos mais agressivos com relação à venda, seja ela de um produto físico ou serviço. Assim, o trabalho explica a pesquisa de Brinkman e Kirschner, relembra os conceitos de marketing que norteiam o comportamento do consumo e depois elabora um plano estrateégico para lidar com esses comportamentos difíceis, que virarão consumidores difíceis.
\end{abstract}

Palavras-chave: marketing; comportamento de consumo; comportamentos difíceis; consumidores difíceis; consumo; comportamento humano.

\section{Dealing with difficult clients. Revisiting the work of Dr. Rick Brinkman and Sr. Rick Kirschner on customer satisfaction}

\begin{abstract}
Regardless of the means of purchase, with difficult behaviors, especially when whether physical or not, one can face se- the seller cannot meet their needs and inrious problems with regard to customers tentions. Dr. Rick Brinkman and Dr.
\end{abstract}


Rick Kirschner studied human behavior to better understand difficult behaviors and managed to rank ten difficult behaviors, based on their intentions and focus. The aim of this work is to use the studies of the authors to better understand our customer's behavior when their needs are not met, thus generating discomfort and more aggressive behavior with respect to the sale, be it a physical product or service. Thus, the work explains the research of Brinkman and Kirschner, recalls the marketing concepts that guide the consumption behavior and then draw up a strategic plan to deal with these difficult behaviors, which will turn into difficult customers.

Keywords: marketing; consumer behavior; difficult behaviors; difficult customers; consumer; human behavior.

\section{Introdução}

$\mathrm{Q}$

UANDO falamos de comportamento de consumo, não podemos esquecer que antes de qualquer coisa existe o comportamento humano, que norteia todo o comportamento de consumo e faz com que o cliente finalize ou não a tarefa de comprar. Isso significa que estudar o comportamento de consumo significa entender o comportamento humano baseado em suas intenções e definir melhor quais ações utilizaremos para atingir nosso público alvo.

Assim, entender o comportamento do consumidor por uma abordagem da psicologia pode nos levar a ter mais sucesso em nossas vendas, principalmente quando se trata da relação cliente $\mathrm{x}$ vendedor. É necessário entender o comportamento humano para escolher a melhor abordagem de vendas. Podemos dizer que o comportamento de consumo é reflexo do comportamento humano e diário que faz com que o indivíduo compre ou não o produto, o serviço ou a ideia proposta.

Dr. Rick Brinkman e Dr. Rick Kirschner realizaram um estudo baseado na intenção e assertividade humana para entender melhor o comportamento humano. Eles chegaram à conclusão de que existem dez comportamentos difíceis de lidar, mas que podem ser trabalhados e entendidos. Não que exista somente esses dez comportamentos difíceis, mas é um norte para entender melhor os motivos que levam alguém a reagir de maneira mais agressiva ou não. 
Para esse projeto propõe-se um estudo de comportamento de consumo trazendo para o Marketing as descobertas do Dr. Rick Brinkman e Dr. Rick Kirschner. Com essa abordagem e os estudos de Philip Kotler, o objetivo deste trabalho é entender esses comportamentos e como fazer com que eles não atrapalhem as vendas, ou que sejam ferramentas de auxílio na hora de fechar um negócio. Portanto, trata-se de entender o comportamento humano, aos olhos do Dr. Rick Brinkman e Dr. Rick Kirschner, entender o que o Marketing nos propõe com relação ao comportamento de consumo e unir os dois estudos para lidar melhor com clientes difíceis.

\section{Consumo}

Assim, é necessário entender o consumo do ponto de vista do marketing para que haja um entendimento melhor do comportamento do consumidor. $\mathrm{O}$ consumo pode ser de algo físico (um carro ou um sapato) ou de um serviço (curso de Inglês ou massagens terapêuticas). Segundo Kotler (1994), "Marketing é um processo social e administrativo pelo qual indivíduos e grupos obtêm o que necessitam e o que desejam através da criação e troca de produtos e valor com outras pessoas".

\section{Visão Geral do Consumo}

O marketing tem se utilizado de ferramentas diferentes para se adaptar aos novos consumidores, que aliado às novas tecnologias, têm ampliado o poder de compra e negociação. O marketing tem acompanhado as mudanças de época e de público em que se encontra. A figura 1 (Evolução do Marketing) mostra como o marketing foi evoluindo até a década de 90 . 
Figura 1. Evolução do Marketing

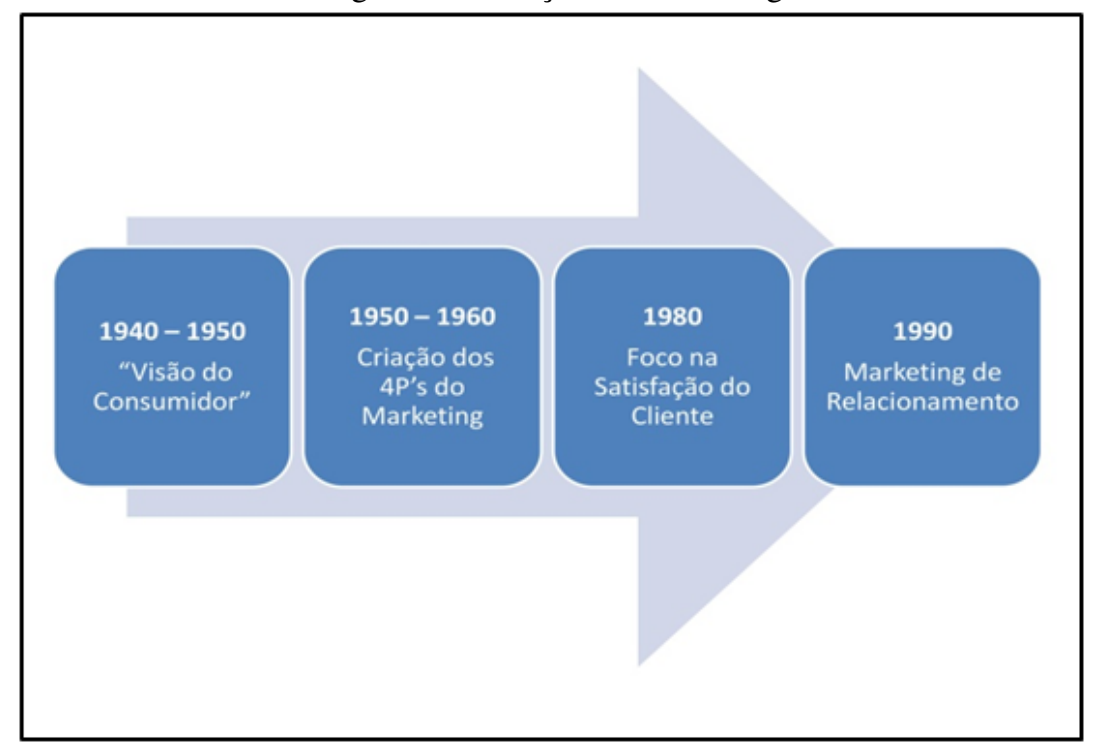

A partir dessa data, a era da tecnologia começou a dominar os consumidores e a necessidade da criação de novos conceitos de marketing foi sendo suprida, como é o caso do "marketing digital" que surge devido o crescimento da tecnologia na vida do consumidor, o que o faz tomar decisões diferenciadas com relação a compra de um produto ou serviço.

Em resumo, o marketing não mudou e a necessidade de se ter um produto ou utilizar um serviço também não mudaram. O que muda é a perspectiva dos produtos e a forma como a empresa levará essa informação até o consumidor, para que esse possa adquirir seu produto ou serviço. Temos lados positivos e negativos com relação a toda essa mudança. Um exemplo disso é o aumento dos meios de comunicação que fazem com que o consumidor final fique sabendo do produto ou serviço mais rápido (por meio de tablets, smartphones, entre outros dispositivos eletrônicos). Isso aumenta a concorrência e pode fazer com que a qualidade no atendimento tenha uma queda perceptível para o cliente, já que há uma necessidade no corte de custos e na venda em massa para poder suprir toda a necessidade da empresa. 
Por esse e outros motivos, o marketing deixou de ser tradicional para assumir uma forma mais "engajadora", que chamaremos de "marketing de engajamento", no qual a marca cria um relacionamento direto com o consumidor para que este possa opinar e fazer com que a empresa crie um relacionamento mais duradouro com seus clientes de um modo que eles não se sintam violados no seu direito de opinar ou trocar de marca. No livro escrito pelo CEO da Constant Contact, "Engagement Marketing: How Small Business Wins in a Socially Connected World" (Gail F. Goodman, 2012)8, o autor classifica três pontos que devem ser seguidos para que o marketing de engajamento seja um sucesso, os quais são: 1) criar uma experiência inovadora no cliente; 2) montar estratégias para que o cliente mantenha contato usando sua experiência inicial, e 3) engajar pessoas com conteúdos que as inspirem e as coloquem numa posição ativa de propagar a marca. Baseado nesses três passos, o autor simplifica a maneira de se utilizar o marketing de engajamento. Por esse meio, o envolvimento do cliente com a marca passa a ser maior refletindo o que a marca tanto espera: fidelização do cliente. A figura 2 (Marketing de Engajamento) mostra alguns pontos que foram mudando para que o marketing de engajamento ganhasse espaço.

Figura 2. Marketing de Engajamento

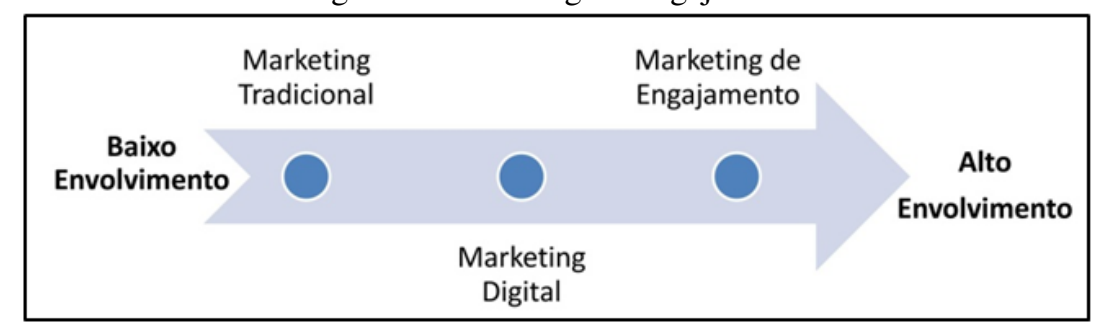

Como exemplos, podemos citar a televisão, os jornais e o rádio como forma de comunicação do marketing tradicional. Já no marketing digital, podemos citar sites, e-mails, redes sociais, entre outro. O que difere o marketing digital do marketing de engajamento é a comunicação entre empresa e consumidor para torná-lo cada vez mais fiel a sua marca, ou seja, a marca cria um "diálogo" para atender melhor seu cliente. 


\section{O Consumidor}

O consumidor por sua vez tem assumido novas abordagens de compras, já que a tecnologia trouxe uma série de novas possibilidades de comunicação. Pode-se entender melhor lembrando que os canais de venda eram muito reduzidos e cresceram em uma velocidade rápida. $\mathrm{O}$ ambiente corporativo, que antes ficava distante do consumidor final, foi se aproximando dele pelas ferramentas sociais, tornando o consumidor mais participativo e exigente. Isso faz com que o maior desafio das empresas seja fidelizar os clientes entendendo esse cenário.

O consumidor, ao longo do tempo, passou por uma transformação bastante significativa que acompanha a evolução da tecnologia e das mídias sociais. O consumidor tinha apenas um canal de compra, ou seja, a loja que tinha o poder do produto. Quando a era digital começou a ganhar força, o cliente se transformou em um "consumidor multicanal", pois poderia fazer compras pelo telefone, e um pouco mais tarde pela internet também. Com a popularização das redes sociais e o crescente número de aparelhos tecnológicos, o consumidor passa a ser chamado de "omni-channel" pelo e-commerce, pois além de comprar pelo smartphone, utiliza as redes sociais para dar suas opiniões, fazer seus pedidos e se comunicar diretamente com o fabricante do produto.

O consumidor passa a ter o poder total do produto, que antes era do estabelecimento que o vendia. Ele pode fazer uma revolução em uma marca por apenas colocar suas opiniões em uma rede social e essa se tornar um marketing viral. Um exemplo bem prático com relação a isso é o ocorrido com a Coca-Cola e o rato12. Um consumidor postou uma foto onde aparecia um rato dentro de uma garrafa de Coca-Cola. Na época virou marketing viral e todos só falavam dos ratos que poderiam estar em outras garrafas. A CocaCola resolveu esperar laudos que comprovassem o que o consumidor havia reclamado, e o resultado foi que a história era falsa. Mesmo o fato não sendo verídico o consumidor que começou essa história utilizou de redes sociais para isso, fazendo com que a história fosse transmitida em tempo rápido para uma quantidade muito grande de pessoas.

Fernando Lucena, consultor e presidente do Grupo Friedman, nos apresenta uma maneira de entender melhor nosso comportamento moderno, que ele chama de "Matemática do Novo Consumidor"11, que segue a seguinte or- 
dem: o atual consumidor tem menos tempo (T) e gasta menos dinheiro (D) em suas compras, porém tem mais opções (O) de escolha e informações (I) sobre os produtos. O resultado dessa matemática é o que ele chama de Potencial de Compra (PC). Veja modelo:

$$
\mathrm{PC}=\mathrm{T}(-)+\mathrm{D}(-)+\mathrm{O}(+)+\mathrm{I}(+)
$$

\section{A Empresa}

A empresa por sua vez tem o papel de fornecer o produto e/ ou serviço ao consumidor final. Essa é uma visão bem simplificada do papel da empresa no processo do comportamento do consumidor. A empresa exerce um papel mais que fundamental pois ela também fornece tudo aquilo que vai envolver o cliente para leva-lo a finalizar sua compra.

Os 4 Ps do marketing9 descrevem bem a importância da empresa com relação ao comportamento de consumo. Cada "P" influencia de alguma maneira a escolha que o consumidor vai fazer com relação à compra e pode significar um avanço na conquista de mercado e na consolidação da marca.

- PRAÇA: se refere ao local onde o produto está disponibilizado para que o cliente compre. Nesse caso pode ser em um espaço físico ou online, dependendo do segmento da loja e do produto;

- PREÇO: refere-se ao valor atribuído ao produto, sabendo que esse pode variar dependendo do material que é fabricado até o valor que é gerado por uma marca e pela sua representação no mercado;

- PRODUTO: refere-se às características do produto e seu diferencial para que esse possa ser comercializado;

- PROMOÇÃO: refere-se a como o produto será conhecido pelo seu público-alvo. Um exemplo de promoção é uma campanha feita pelo Facebook para divulgar um novo produto da marca ou uma atualização do mesmo.

É importante lembrar que todos os pontos são planejados baseados no tipo de cliente que se deseja atingir. Assim, o PREÇO pode ser menor porque a classe atingida é a classe D e E, fazendo com que todos os outros Ps tenham de ser adaptados para essa realidade. Nesse caso, os estabelecimentos que venderiam esse produto (PRAÇA) devem ser em locais onde a concentração dessa classe seja maior. O PRODUTO pode ser de qualidade inferior por redução de 
custos e os meios de como esses produtos serão conhecidos (PROMOÇÃO) podem ser de diversas formas, inclusive pela internet. A Figura 3 resume algumas questões que cada $\mathrm{P}$ do Mix de Marketing traz consigo para que possa ser mais eficaz na hora do planejamento.

Figura 3. Marketing Mix

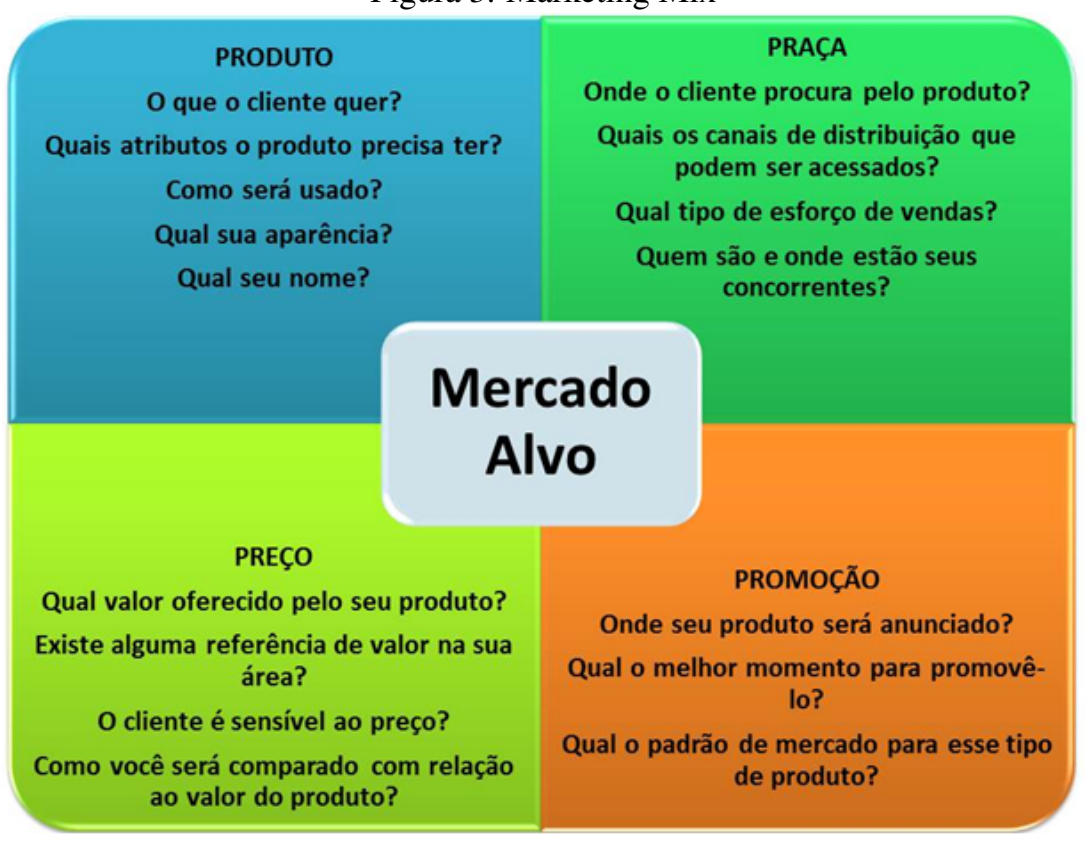

Além do Mix de Marketing, o autor Conrado Adolpho, criou os 8 Ps do Marketing Digital para que houvesse mais ferramentas a serem usadas com o avanço da tecnologia. Isso auxilia a empresa na hora de pensar em ações de marketing digital, sejam elas em qual "P" do Mix de Marketing ela esteja focada ou planejando.

- PESQUISA: direcionar os esforços com base no comportamento online do consumidor;

- PLANEJAMENTO: para definir como o site da empresa se transformará em uma ferramenta de negócios;

- PRODUÇÃO: executar o planejamento estipulado no segundo P; 
- PUBLICAÇÃO: escolher conteúdos com as diretrizes da SEO (Search Engine Optimization);

- PROMOÇÃO: produzir conteúdos importantes que possam se tornar virais;

- PROPAGAÇÃO: provocar o compartilhamento de todo o processo descrito antes;

- PERSONALIZAÇÃO: criar relacionamento por meio da personalização feita pela segmentação do público-alvo;

- PRECISÃO: medir os resultados obtidos para auxiliar nos próximos planejamentos.

Como visto, o sistema criado pelo Conrado Adolpho se trata de um ciclo que deve ser seguido para que o sucesso seja atingido. O marketing digital não descarta as ferramentas do marketing tradicional, mas tem a necessidade de adaptar algumas e criar novas para atender o público que vem incorporando no seu dia-a-dia a tecnologia como estilo de compras. A figura 4 exemplifica esse sistema criado por Conrado Adolpho.

Figura 4. 8 Ps do Marketing Digital

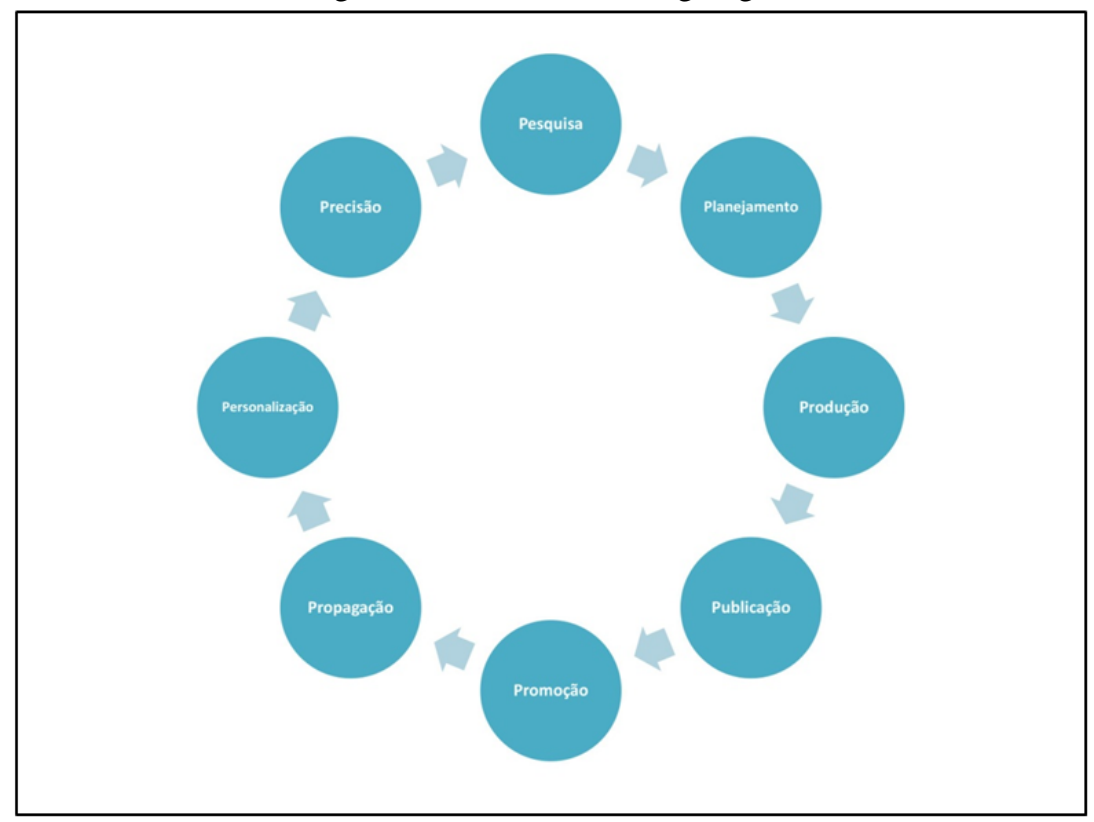




\section{O Atendimento}

Pode-se assim entender que o atendimento depende de uma série de fatores para que se tenha sucesso nas vendas. $\mathrm{O}$ atendente (ou o vendedor) é a ponte entre o cliente e a empresa. Mesmo em situações de compras online, existe alguém que vai servir de suporte para que essa compra seja efetuada. Segundo a Sociedade Brasileira de Coaching, um bom atendimento depende de sinceridade, transparência, satisfação, entender o outro lado, desenvolvimento de pós-venda e fazer com que o cliente se sinta à vontade. Esses pontos servem como ponto de partida para que o atendimento seja eficaz e eficiente. Além disso, a empresa deve fornecer uma boa estrutura para que o atendente possa exercer sua função da melhor maneira possível. Isso significa que mesmo que o colaborador tenha excelentes técnicas de vendas, se a empresa não lhe der um bom suporte (pode-se citar aqui um treinamento específico sobre os 4 Ps do marketing para aquele produto, boa remuneração, possibilidade de crescimento interno, entre outros), a venda pode não acontecer.

O cliente, com tantas opções, já não é mais aquele que passa despercebido por um erro cometido pela empresa ou pelo vendedor. Com as ferramentas de mídias sociais, o cliente tem muito mais poder que antes e o atendimento deve sempre prezar por uma qualidade para seja referencial da empresa. $\mathrm{O}$ site Reclame Aqui é um exemplo de uma ferramenta que mostra o quanto os atendimentos tem sido insatisfatórios por diversos motivos. Por isso, é necessário se atentar a todas as etapas do processo de uma venda para que o cliente esteja satisfeito e seja fidelizado.

Portando o consumo sempre terá o mesmo objetivo: a venda e compra de um produto ou serviço. O que muda é a necessidade de se adaptar a novas tecnologias e públicos que podem ou não fechar a compra por algum motivo. As novas ferramentas estão sendo cada vez mais aperfeiçoadas para que a compra satisfaça a necessidade e o desejo do cliente.

\section{Comportamentos}

A pesquisa citada nesse trabalho foi baseada nas experiências do Dr. Rick Brinkman e do Dr. Rick Kirschner, estudantes do comportamento humano e palestrantes motivacionais, que se juntaram para fazer uma pesquisa sobre 
Como lidar com clientes difíceis. Uma releitura do trabalho do Dr. Rick Brinkman e Dr. Rick Kirschner voltado para o atendimento ao cliente

comportamentos difíceis. Sua pesquisa foi baseada em estudos e relatos de clientes que atendiam individualmente para desenvolvimento pessoal e profissional.

\section{Intenções}

Segundo Dr. Rick Brinkman e Dr. Rick Kirschner, o que norteia o comportamento do ser humano são suas intenções. Para definir melhor essas intenções, eles se utilizam de dois pontos importantes no comportamento humano: o nível de assertividade e o foco de atenção. Todo ser humano tem um ambiente que os doutores chamam de "zona de normalidade" que é quando elas conseguem lidar com as situações sem que seus comportamentos sejam difíceis e, muitas vezes, incontroláveis.

O nível de assertividade diz respeito ao quanto à pessoa é agressiva ou passiva com relação a suas atitudes. Enquanto o foco de atenção diz respeito a que direcionamento está sua ação: se é na tarefa ou nas pessoas.

Observe a imagem (Figura 5 - Zona de Normalidade) que descreve esse ambiente de "zona de anormalidade", assertividade e foco de atenção.

Figura 5. Zona de Normalidade

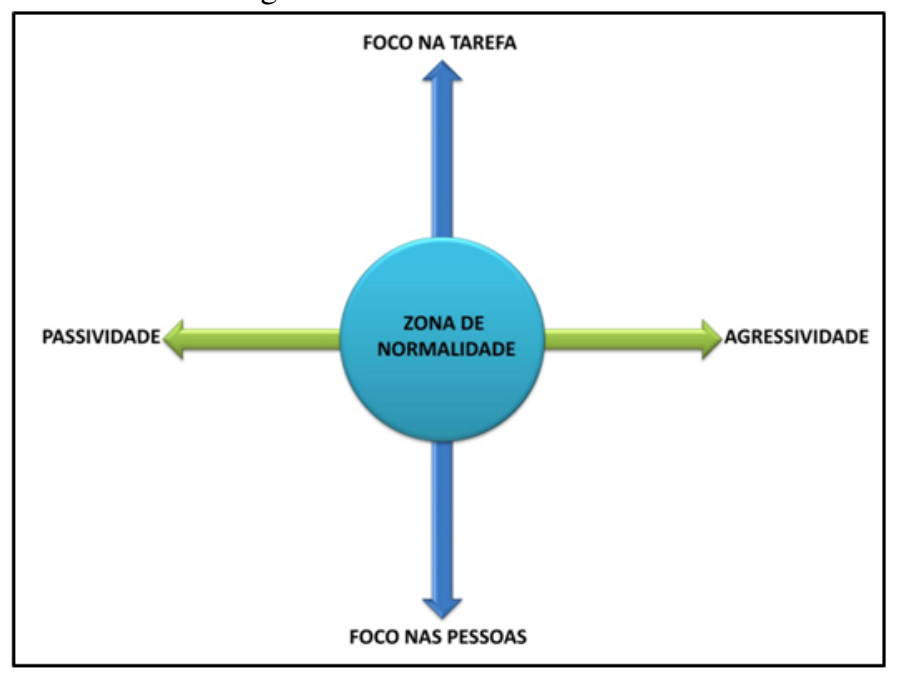


Baseado nessa imagem, podemos classificar quatro intenções positivas, dependendo do grau de assertividade e foco de atenção. A zona de normalidade significa o espaço em que o indivíduo consegue se controlar e suprir suas intenções sem problema algum.

$\mathrm{O}$ indivíduo que é focado na tarefa e tem sua assertividade mais passiva, tem a intenção de "fazer as coisas certas", já o que é mais agressivo em sua assertividade, a intenção é de "finalizar a tarefa". Aqueles com foco em pessoas e assertividade mais passiva tem a intenção de "integrar-se às pessoas", já o mais agressivo tem sua intenção de "ser reconhecido". Não existe nada de errado nessas intenções e comportamentos. Para simplificar, veja a figura 6 (Intenções Positivas) como elas se encaixam no quadro da zona de normalidade.

Figura 6. Intenções Positivas

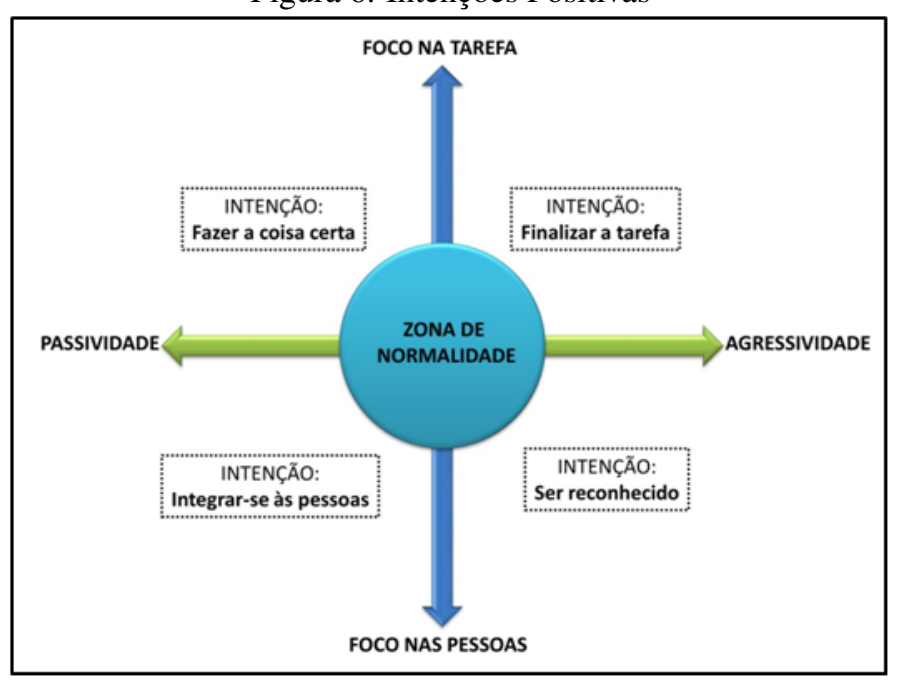

- Finalizar a Tarefa: seu objetivo é finalizar aquilo que começou. Não que os outros pontos não importam, mas seu foco é fazer com que a tarefa seja finalizada no prazo estipulado, não pensando em detalhes ou pessoas.

- Fazer a coisa certa: pode-se até cumprir o prazo, mas enquanto não tiver segurança o suficiente em que a tarefa foi realizada da maneira correta, 
a intenção não satisfeita, por isso, pode até atrasar tarefas e não pensar tanto nas pessoas.

- Integrar-se às pessoas: pode deixar seus desejos de lado para atender o desejo das outras e se sentir parte do grupo.

- Ser reconhecido: o objetivo é buscar reconhecimento. Esse reconhecimento pode vir de diversas formas. Quando o reconhecimento acontece de fato, essa intenção pode tirar suas energias da tarefa e, assim, entregar fora do prazo ou até mesmo contendo erros.

Não há nada de errado nessas intenções ou os comportamentos que elas norteiam. O problema está quando essas intenções não são supridas e acabam saindo da Zona de Normalidade e entram na Zona de Estresse, ou Zona Cinzenta, como diz Dr. Rick Brinkman e Dr. Rick Kirschner.

\section{Comportamentos Difíceis}

Deve-se lembrar de que, segundo o behaviorismo, as pessoas podem associar as respostas de estresse dependendo da experiência que tiveram no passado visto que estas situações as prejudicaram ou causaram certo estresse. Essa é uma fobia clássica que pode ser desenvolvida. Um exemplo seria um aluno que não passou no exame final e pode ter algum tipo de reação de estresse quando entrar na sala onde fez a prova, por associar a sala a um local de estresse e fracasso. Alguns comportamentos difíceis são apenas reações naturais do indivíduo que desenvolveu esse medo por algum motivo, e os medos podem custar a desaparecer. Como não sabem enfrentar ou lidar com a situação, acabam fugindo dela e apresentando algum tipo de comportamento que pode ser difícil de lidar.

A Zona de Estresse, ou Zona Cinzenta, se caracteriza pela não realização das intenções. Cada indivíduo reagirá de uma maneira em determinada situação, mas seu comportamento será difícil porque, além de sua frustração, ele vai usar "armas" que podem prejudicar o relacionamento com outras pessoas e qualquer processo em que esteja envolvido, seja de planejamento ou de venda. Observe na Figura 7 (Zona Cinzenta), onde isso pode ocorrer. 
Figura 7. Zona de Estresse (ou Zona Cinzenta)

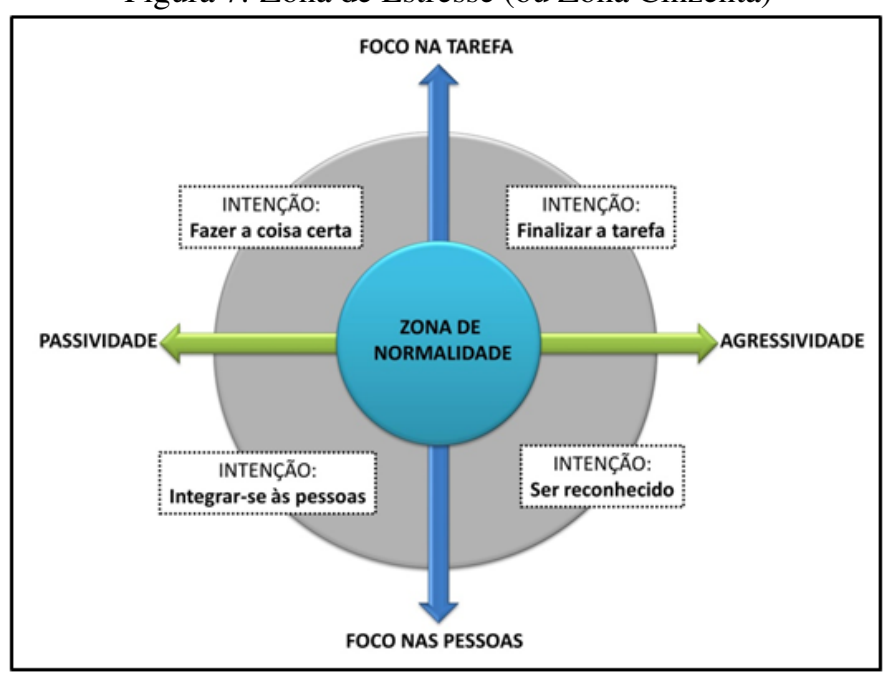

Isso significa que a intenção da pessoa não foi realizada, portanto, ela entra em uma zona de estresse onde pode desenvolver um comportamento difícil e muitas vezes destrutivo psicologicamente. Assim, quando a intenção de "fazer a coisa certa" não é realizada, o estresse se volta para o perfeccionismo, assim como a intenção de "finalizar a tarefa" se volta para o controle, a intenção de "integrar-se às pessoas" se torna uma conquista à aprovação e de "ser reconhecido" se torna um desejo de atrair a atenção dos outros. 
Figura 8. Intenções não realizadas

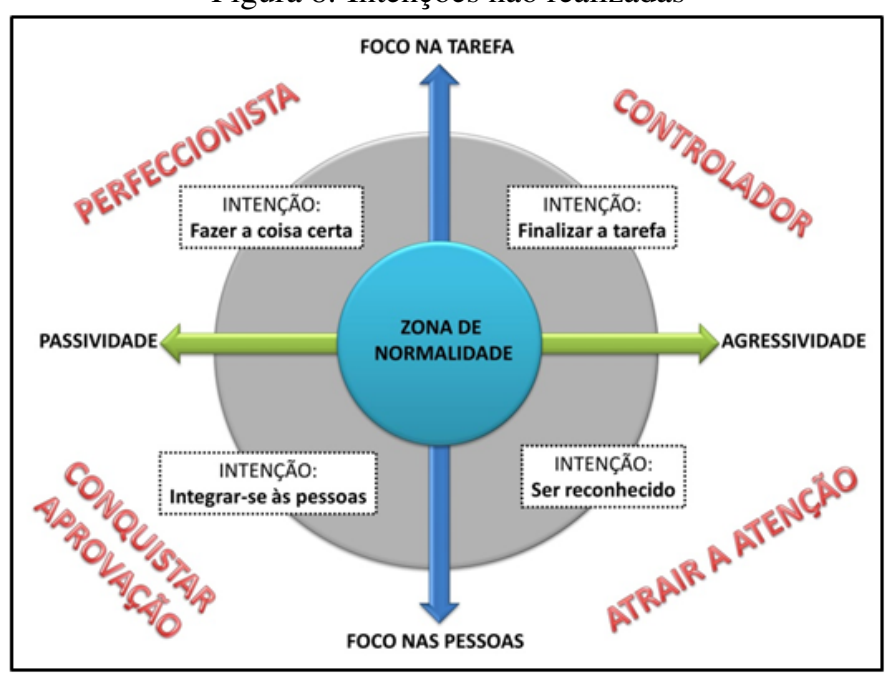

Baseado nessas intenções não realizadas, os autores classificaram dez comportamentos difíceis. Abaixo, a lista dos dez comportamentos e um resumo de cada comportamento.

- O tipo "tanque de guerra": agressivo e, para ele, os fins justificam os meios. Você será eliminado se estiver em seu caminho. Você acaba se tornando o obstáculo quando se interpõe entre ele e o objetivo, e isso não é nada pessoal.

- O tipo "atirador de elite": dissimulado, acumula informações negativas contra você para usar em momentos de estresse. Não atira para todo lado, sabe bem quem quer atingir. E o faz pelo mesmo motivo do "tanque de guerra": eliminar obstáculos.

- O tipo "granada": com seus acessos de raiva, explode como uma granada sem ver quem está atingindo. Isso acontece na mesma maneira de uma granada: primeiro se tira o pino, depois ele explode do nada e atinge até mesmo quem não tem nada a ver com a situação.

- O tipo "sabe-tudo": sabe de quase tudo, passa horas falando dos seus conhecimentos, mas não dará ouvido para o que você precisa falar ou comunicar, por achar a opinião dos outros inferior. Seria um jeito de 
fazer com que os outros se calem, já que ele os percebe como um obstáculo também.

- O tipo "ele-pensa-que-sabe-tudo": pensam que sabem tudo e se você deixá-los conduzir as ações sem conhecimento do assunto pode levar o projeto a falência já que eles não sabem muito do assunto. Comportamse assim para que você dê atenção a eles.

- A pessoa "sim": faz de tudo para agradar a todos dizendo "sim" para tudo. São lentas para agir e geralmente não cumprem o que prometem por terem dificuldade em dizer "não" e priorizar tarefas. As tarefas acabam se tornando obstáculos para, positivamente, chamar a atenção.

- A pessoa "talvez": tem dificuldade em tomar decisões, então elas esperam que as decisões se resolvam por si só. Assim elas não correm o risco de chatear ninguém, pelo menos é o que elas pensam.

- A pessoa "nada": não dá feedback algum porque não faz nada, fica como "invisível". Essa é uma maneira que eles encontram para não dispor com a outra pessoa.

- A pessoa "não": desencorajador, usa a desculpa de estar sendo realista e não pessimista, mas acaba atrapalhando o andamento de projetos com seus desesperos negativos.

- O "reclamador": afundado em um mar de desilusões, reclama de tudo da vida e não faz nada. Em seus entendimentos, tudo dará errado até que alguém faça alguma coisa para mudar isso. Assim, acha que não será culpado quando tudo sair errado.

Esses dez comportamentos podem ser vistos em diversas intenções não realizadas. Observe a figura 9 (comportamentos difíceis), onde estão os comportamentos difíceis gerados em cada intenção não realizada. 
Como lidar com clientes difíceis. Uma releitura do trabalho do Dr. Rick Brinkman e Dr. Rick Kirschner voltado para o atendimento ao cliente

Figura 9. Comportamentos Difíceis

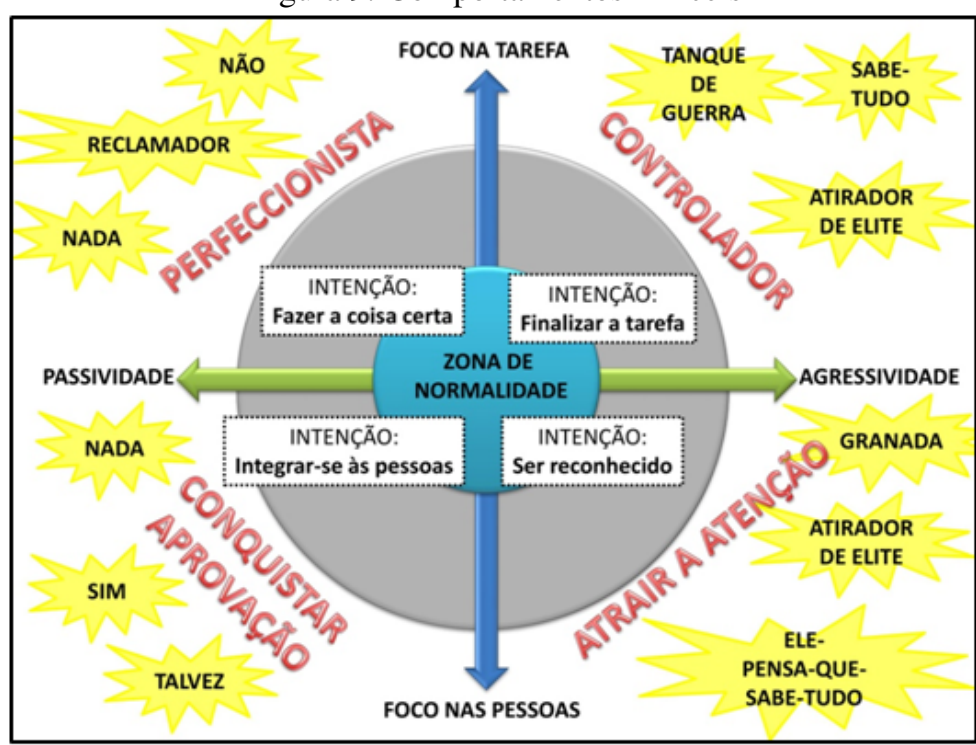

Baseado na imagem anterior pode-se entender melhor quais intenções não foram satisfeitas para que o comportamento gerasse um estresse. Segue tabela com um breve resumo das intenções, dos comportamentos difíceis e qual a reação que esse comportamento pode ter como sinal da intenção não satisfeita. Vale lembrar que essa é uma pesquisa comportamental e que pode haver outras que podem complementar esse estudo. 
Tabela 1. Intenções, Comportamentos Difíceis e Possíveis Reações

\begin{tabular}{|c|c|c|}
\hline \multicolumn{1}{|c|}{ Intenção } & Comportamento & Possível Reação \\
Finalizar a Tarefa & Tanque de Guerra & Violência \\
\hline Finalizar a Tarefa & Atirador de Elite & Comentários virulentos \\
\hline Finalizar a Tarefa & Sabe-Tudo & Aulas autoritárias \\
\hline Fazer a Coisa Certa & Reclamador & Lamentos \\
\hline Fazer a Coisa Certa & Pessoa "não" & Negatividade \\
\hline Fazer a Coisa Certa & Pessoa "nada" & Passividade \\
\hline Integrar-se às Pessoas & Pessoa "nada" & Passividade \\
\hline Integrar-se às Pessoas & Pessoa "sim" & Afabilidade \\
\hline Integrar-se às Pessoas & Pessoa "talvez" & Indecisão \\
\hline Ser Reconhecido & Granada & "Barullhos" \\
\hline Ser Reconhecido & Atirador de Blite "amigável" & Piadas corrosivas \\
\hline Ser Reconhecido & Ble-Pensa-Que-Sabe-Tudo & Orgullho \\
\hline
\end{tabular}

"Se você trabalha com pessoas difíceis, saiba que há uma boa e má notícia. A má é que você trabalha com elas. A boa é que você tem tempo para estudá-las, entender seus padrões de comportamento e planejar uma resposta estratégica." (Dr. Rick Brinkman e Dr. Rick Kirschner, pg. 77, 2006)

\section{Lidando com clientes difíceis}

\section{Identificando as Necessidades e os Desejos do Cliente}

Segundo Abraham Maslow, as necessidades humanas são divididas e classificadas em forma de pirâmide. 
Figura 10. Pirâmide das Necessidades Humanas

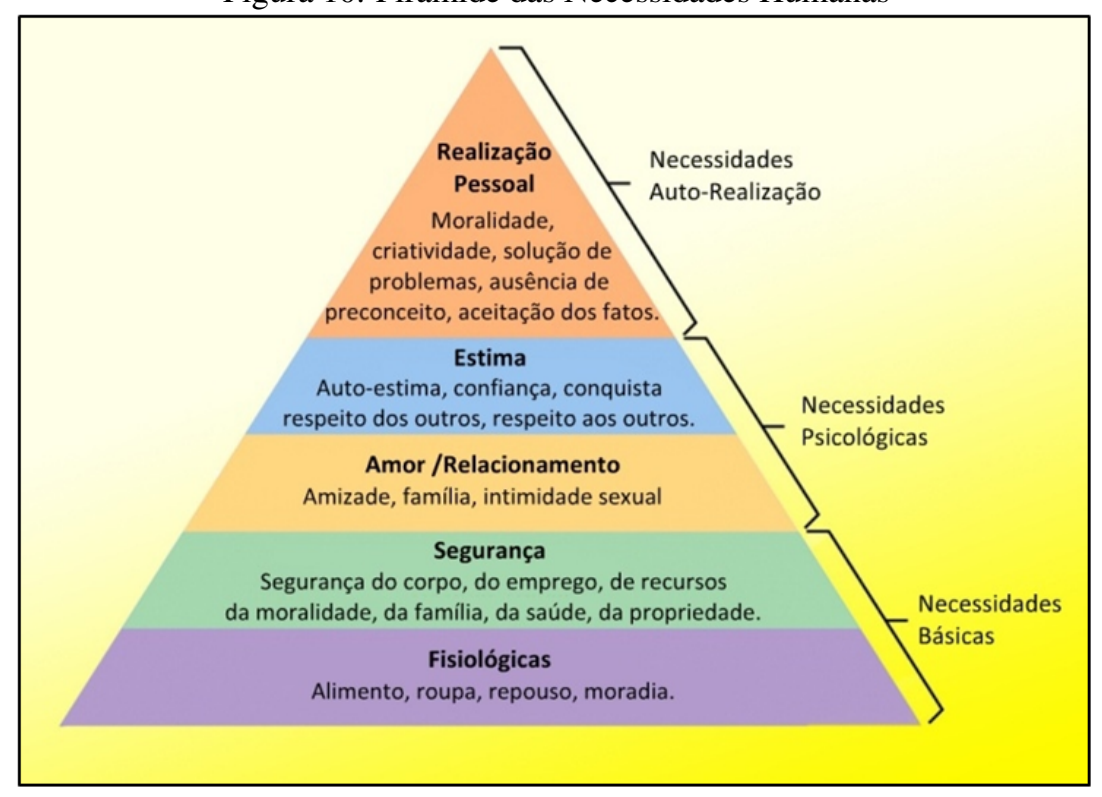

O que se deve destacar é que as necessidades humanas são colocadas em forma de pirâmide porque se a base não for satisfeita, o restante não serão também, ou serão apenas parcialmente. O cliente pode procurar um produto para satisfazer qualquer necessidade da pirâmide. Vale resaltar que necessidade é o que ele precisa para sobreviver, enquanto desejo é o que ele prefere. Um bom exemplo é a comida. O ser humano tem a necessidade de comer quando está com fome, porém pode optar por comer em um restaurante de fast-food ou cozinhar em casa, dependendo do seu desejo. Um dos papéis do marketing é também estimular desejos para que o cliente adquira o produto ou serviço que é oferecido.

O entendimento deve ser feito com muita cautela para que o cliente esteja satisfeito com a compra e se fidelize na marca ou loja, e isso pode significar que sua necessidade não esteja em comprar um determinado produto. Com a falta de diálogo nos dias de hoje alguns clientes se tornam fiéis a certos estabelecimentos porque recebem a atenção que necessitam, logo acabam comprando algo que desejam, seja um sapato, um livro ou até mesmo se matricular em um curso. Por isso, há a necessidade de entender o cliente e perceber 
aquilo que ele necessita e o que ele deseja naquele momento, para que o produto e o serviço prestado possam ir de encontro com o que ele busca.

\section{Satisfazendo o Cliente}

Satisfazer o cliente significa entender sua realidade e oferecer aquilo que ele necessita e deseja. O cliente deve ser ouvido e ter suas dúvidas sanadas para que o vendedor possa compreendê-lo melhor e fazer com que este se fidelize na marca. Portanto, cabe ao vendedor ter habilidades específicas de atendimento, como saber ouvir e fazer perguntas certas, para que seu trabalho seja feito de forma eficaz e eficiente. Nem todo cliente fechará a venda, mas levará consigo a impressão que teve do atendimento, do clima do estabelecimento, da organização e de todos os detalhes possíveis, mesmo que inconscientemente.

O maior problema é que as metas têm sido consideradas necessidades primárias das organizações. Com isso, o atendimento se torna cada vez menos satisfatório e o cliente, sabendo da possibilidade de opções, acaba comprando em outro local. Isso se deve a diversos fatores, entre eles má condições de trabalho, má remuneração, líderes que não compreendem as necessidades básicas dos colaboradores. Segundo PROCON, em 2014, as empresas que mais tiveram reclamações de atendimento foram as de telefonia. As reclamações vão desde cobranças indevidas, até problemas com aparelhos e sinais.

$\mathrm{O}$ grande diferencial das empresas pequenas tem sido o atendimento, segundo pesquisa do SEBRAE de 2014, pois prezam por um atendimento individualizado para compreender melhor a necessidade e o desejo do cliente. Segundo artigo publicado na Business Analytics de Portugal, em 23 de fevereiro de 2015, o consumidor moderno tem 7 características: compras a contra-relógio, controle, compras por diversos canais, consumidores de conteúdo, experiência global, colaboradores e social shares. Sahal Laher, vicepresidente executivo e Chief Information Officer, Brooks Brothers, disse sobre e-commerce: "Não importa onde está a fazer as suas compras, o consumidor é o consumidor. Há que quebrar as barreiras entre canais, capacitar o consumidor de forma uniforme e envolve-lo no seu site como se estivesse na sua loja." 


\section{Como Lidar com Clientes Difíceis}

Segundo Dr. Rock Brinkman e Dr. Rick Kirschnerr, existem dicas básicas para lidar com comportamentos difíceis antes de apontar a melhor reação para os dez comportamentos citados por eles.

- Reduza as diferenças: as diferenças não devem ser vistas como obstáculos, mas como desafios a serem reduzidos para que a comunicação seja clara e todos possam compreender melhor e atender as necessidades ou desejos do cliente. Estabelecer afinidades pode ser uma maneira de reduzir diferenças, lembrando sempre que o profissionalismo deve sempre vir em primeiro lugar. E isso significa transformar as diferenças em cooperação. Afinal de contas, o objetivo da venda é a mesma: o cliente comprar, e o vendedor vender.

- Escute para ser realmente entendido: isso significa que se deve escutar antes de fazer com que o cliente entenda a marca ou o produto. Para isso, é necessário fazer perguntas para que o cliente possa expressar aquilo que realmente necessita. A discussão acontece porque duas pessoas querem ser ouvidas e ninguém quer escutá-las. Saber escutar pode abrir caminhos para novos negócios.

- Atinja uma compreensão mais profunda: não se deve aceitar um comportamento ou simplesmente ser preconceituoso com relação a isso. A compreensão faz com que novos caminhos sejam direcionados para a solução do problema. Para isso, é necessário estudar e estar sempre atento aos sinais que demonstram os desejos e as necessidades do cliente.

- Fale para ser compreendido: depois de escutar e compreender o cliente, uma conversa com bons argumentos é a solução para que o cliente não se sinta ameaçado. As cinco técnicas apresentadas pelos autores da pesquisa são: monitore seu tom de voz, apresente sua intenção principal, interrompa diplomaticamente, diga a sua verdade e seja flexível.

- Projete e espere o melhor das pessoas: as pessoas tendem a se comportamento conforme suas expectativas com relação a elas. Isso não significa que elas farão exatamente o que você deseja que elas façam, mas se você esperar algo positivo delas e demonstrar isso, a tendência é que elas terão comportamentos positivos, e vice-versa. Os autores 
dizem que "é fato que as pessoas melhoram ou pioram de acordo com suas expectativas e projeções".

Nem sempre é fácil lidar com comportamentos difíceis. Às vezes pode não ser tão complicado pelo fato de já termos passado por algo semelhante e, por isso, já temos uma abordagem para tal comportamento. Os dez comportamentos difíceis, listados pelos pesquisadores, são: "tanque de guerra", "atirador de elite", "granada", "sabe-tudo", "ele-pensa-que-sabe-tudo", "sim", "talvez", "nada", "não" e "reclamador".

- Tanque de Guerra: manter sempre a posição é uma das maneiras de lidar com esse comportamento, mas o objetivo é interromper o comportamento fazendo com o cliente volte sua atenção ao que realmente importa e comece a se acalmar. No lugar de contra-atacar, a defesa nesse caso é a explicação e a justificativa da venda do produto ou serviço. $\mathrm{O}$ importante é não ficar paralisado e ir contornando a situação até que o comportamento vai desaparecendo dando espaço para um novo diálogo, ressaltando que ele só respeita quem se impõe a ele.

- Atirador de Elite: mantenha sempre sua posição, mas nesse caso, utilize perguntas estratégicas para que o cliente responda e perceba que seu comportamento não está sendo adequado. Perguntas como "quando você disse isso, o que realmente queria dizer?" ou "o que isso teria a acrescentar na nossa negociação?" são perguntas que podem ajudar a "desarmar" o atirador de elite. Lembrando sempre que o profissionalismo, a cordialidade e a compreensão devem sempre estar em destaque em todos os momentos. Caso esse comportamento comece a tomar a forma de um "tanque de guerra", pode-se utilizar a estratégia do mesmo para melhorar a comunicação. Vale ressaltar que uma vez descoberto e visto não faz mai sentido para o "atirador" continuar atirando.

- Sabe-tudo: é necessário que o vendedor entenda muito bem do assunto, pois o "sabe-tudo" pode ser muito questionador. Perceba o que realmente é importante para esse cliente e foque nesse ponto para que ele crie uma harmonia com o vendedor. Colocar o "sabe-tudo" em posição de mentor, apresentando os pontos importantes indiretamente e não ficando ressentido com suas atitudes, pode ajudar no sucesso da comunicação. Não se deve transformar em um "sabe-tudo" para lidar com um, pois isso pode causar ainda mais conflito e estresse. Usando-o a fa- 
vor das vendas, ele pode ser muito positivo, pois de fato ele sabe muito mesmo.

- Ele-pensa-que-sabe-tudo: dar-lhes um pouco de atenção pode ser a chave do sucesso, lembrando sempre que é necessário esclarecer pontos específicos e falar a realidade como de fato ela é. Já que esse comportamento necessita de atenção, ao finalizar a negociação, fazê-la de forma honrosa pode trazer todos os benefícios possíveis para não causar algum tipo de má impressão. A ideia não é humilhá-lo, mas sempre entender sua necessidade de participar.

- Granada: o segredo para lidar com esse tipo de comportamento é prender sua atenção e focar naquilo que realmente o fez "explodir". Assim, a intensidade pode ser reduzida e o "granada" pode evitar ser "detonado" e causar maiores problemas. Escutar com atenção e enxergar esse comportamento de outra forma podem ajudar a fazer um caminho onde a comunicação possa ser mais eficaz. Criar empatia para perceber sua comunicação não verbal e quando o comportamento começa a aparecer dá tempo da pessoa represar seus sentimentos para explodir depois. Isso o faz sentir pior depois, visto ter orientação para pessoas.

- Sim: ter paciência para ser honesto e ajudar esse cliente a fazer um planejamento para finalizar a compra ajuda na comunicação. Além disso, fortalecer o relacionamento para que o cliente tenha confiança no vendedor pode fazer com que esse tenha mais comprometimento com relação à compra. Ele fará a compra se entender que esse é o melhor jeito de agradar o vendedor.

- Talvez: pressionar a pessoa "talvez" não é a melhor solução para que a comunicação seja mais eficaz. Para isso, é necessário estabelecer uma zona de conforto integrando o cliente ao universo da compra, revelar os conflitos e esclarecer todas as opções e criar a possibilidade de manter o contato do cliente, utilizando algum programa de fidelidade do estabelecimento. É importante estabelecer um processo de tomada de decisão, pois a pessoa "talvez" demora um pouco para se decidir com relação à compra. Tudo porque não quer ser desaprovado. Como os anteriores, ela precisa se sentir pertencente, participante do processo todo, pois quer se sentir importante. Entrar no jogo do "não" pode reforçar seu comportamento. O ideal é valorizá-la e depois contestá-la de modo inteligente e não arrogante. 
- Nada: é importante reservar tempo para esse tipo de comportamento. Coloque-se no lugar dela e crie uma conversa para chamá-la a ação da compra. Além disso, faça perguntas abertas mostre satisfação em atendê-la e mostre o futuro como algo promissor, que pode dar certo. $\mathrm{O}$ segredo é andar devagar com esse tipo de comportamento para que ele entre no ritmo da venda e feche o negócio.

- Não: o comportamento da pessoa "não" se reflete na sua resposta negativa antes mesmo de saber como funciona o produto e/ou serviço. Deixe-a livre para ser tão negativa quanto quiser, até que seu negativismo se esgote e os argumentos possam ser discutidos. Não se deve ficar na defensiva, mas apenas ser direto nas respostas e objeções, sempre com muita cautela e cordialidade que também poderá ser percebida pelo fato de deixar a venda em aberta e agradecer a boa intenção do cliente. Outra técnica que pode ser utilizada é fazer observações negativas antes mesmo de o cliente pensar nessa possibilidade, o que podemos considerar um efeito espelho. "Se você não comprar o produto, pode ser que amanhã esteja mais caro" é um exemplo. Ser cauteloso e verdadeiro também são ferramentas fundamentais nesse caso.

- Reclamador: escutar detalhadamente e selecionar os pontos principais são a chave para estabelecer um vínculo com esse cliente. Assim, será mais fácil ser mais específico na hora de uma interrupção e direcionar o foco para soluções. Estabelecer limites com cautela e mostrar os benefícios futuros podem fazer parte das técnicas abordadas para esse tipo de comportamento. Como esse cliente se sente desamparado por um mundo injusto, a tendência das reclamações é um fato natural em sua vida. Por isso, ao lidar com esse tipo de comportamento, seja compreensível ao ponto de levá-lo a reflexão de que, mesmo tudo sem negativo, a compra pode ser algo positivo por diversos aspectos.

Outro aspecto importante ressaltado na pesquisa é o "Efeito Pigmaleão". É o fenômeno que diz que quanto maior as expectativas que se tem com relação a uma pessoa, melhor será seu desempenho. Isso reforça a necessidade de se ter expectativas positivas com relação ao cliente, para que esse possa ter um comportamento mais agradável e menos difícil de lidar. Douglas McGregor 17, doutor em Harvard onde lecionou Psicologia Social, introduziu um estudo na década de 60 com gerentes e colaboradores, onde comprovou que as expectativas positivas da gerência geravam ações positivas dos colaboradores, 
assim também no caso das expectativas negativas. Portanto, se pode aplicar a teoria em organizações, na vida pessoal e, principalmente, no comportamento de consumo.

Para os autores, três dicas são importantes para o sucesso na comunicação:

- Ser um comunicador eficaz: buscar aprendizado e atualização constante faz com que o vendedor se torne cada vez melhor na arte da comunicação;

- Encontrar parceiros de comunicação: envolver-se com pessoas que já tenham essa habilidade bem desenvolvida ajuda a entender melhor as técnicas e a aplicá-las no dia-a-dia;

- Valorizar o que se tem de melhor: isso significa trabalhar as dificuldades e utilizar o potencial ao seu máximo para que se possa, além de ser um bom comunicador, alcançar satisfação pessoal e profissional.

\section{Possíveis Conflitos no Atendimento}

Todo atendimento é cheio de detalhes e pode ser um sucesso ou não, dependendo da maneira como é encarado. Os conflitos são naturais, pois fazem parte de um mundo onde as pessoas são diferentes. Um bom atendimento pode ser resumido em diálogos onde todas as partes saem satisfeitas, satisfazendo suas necessidades e desejos, seja de vender ou comprar um produto e/ou negócio. A negociação é uma técnica que deve ser estudada para ser mais bem aplicada.

Os conflitos então são consequência de ações e comportamentos que não visam a compreensão do cliente de um modo geral. Como os exemplos do PROCON e do SEBRAE, o maior problema está na falta de comunicação entre o cliente e o vendedor, onde todos querem falar e não conseguem ser compreendidos. Os conflitos devem sempre ser administrados com cautela para que possam ser resolvidos da melhor maneira possível. Afinal ambas as partes tem o mesmo propósito: fazer um bom negócio.

\section{Considerações Finais}

Conclui-se que a pesquisa feita pelos Drs. Rick Brinkman e Rick Kirschnerr nos mostra alguns comportamentos indesejáveis que podem ser trabalhados. Conquistar o consumidor tem sido uma tarefa cada vez mais difícil 
nos dias de hoje, mas não tem sido algo impossível. Os comportamentos podem ser trabalhados para que todas as partes envolvidas no processo de venda/compra possam sair satisfeitas da negociação.

Não basta apenas aprender os comportamentos, é necessário ser cordial, saber ouvir e praticar a paciência para que o vendedor possa alcançar uma compreensão cada vez maior do que realmente é importante para o cliente. $\mathrm{O}$ atendimento não depende somente do fato de existir um vendedor, mas da compreensão que ele tem dos comportamentos de seus clientes.

Não existe uma fórmula mágica para lidar com essas situações, o vendedor deve apenas ter disposição para aprender e praticar cada técnica que o levará a ser um melhor comunicador e negociador de um modo geral. Saber se comunicar é uma habilidade que serve para a vida toda.

\section{Referências Bibliográficas}

Atkinson, R.L. (2002). Introdução a psicologia de Hilgard/ Rita L. Atkinson, Edward E. Smith, Daryl J. Bem, Susan Nolen-Hoeksemae Carolyn D. Smith; trad. Daniel Bueno, 13. ed.. Porto Alegre: Artmed.

Bartels, R. (1998). The history of marketing thought. Columbus: Publihing Horizons, 1998.

Bolen, A. (2015). Business Analytics. Sete características do consumidor moderno. Disponível em: http://businessanalytics.pt. Acesso em: $20 \mathrm{de}$ ago. 2015.

Brikman, R. \& Kirschner, R. (2006). Aprendendo a Lidar com Pessoas Difíceis. Primeira Edição. Rio de Janeiro: Sextante. (Série Você S/A, Coleção Desenvolvimento Profissional, Volume 1).

Consumidor Moderno. (s.d.). Como é a experiência do cliente no e-commerce brasileiro?. www.consumidormoderno.com.br. Acesso em: 17 de ago. 2015.

Dica de Escrita (s.d.). Criação de Personagem - Pirâmide de Maslow. Disponível em: www.dicasdeescrita.com.br. Acesso em: 17 de ago. 2015.

Giglio, E. (1996). O comportamento do consumidor e a gerencia de marketing. São Paulo: Pioneira.

Goodman, G.F. (2012). Engagement Marketing: How Small Business Wins in a Socially Connected World. Primeira Edição. EUA: Constant Contact. 
Como lidar com clientes difíceis. Uma releitura do trabalho do Dr. Rick

Kotler, P. (1998). Administração de marketing: analise, planejamento, implementação e controle. São Paulo: Atlas, 5.ed.

Kotler, P. \& Armstrong, G. (1998). Princípios de marketing. Rio de Janeiro: Phb, 7. Ed.

Lucena, F. (2015). Consumidor moderno: faça a conta. Disponível em: www.varejista.com.br. Acesso em: 20 de ago. 2015.

Mata, V. (2015). Como deve ser um bom atendimento ao cliente em sua empresa?. Sociedade Brasileira de Coaching. Disponível em: www.sbcoaching.com.br. Acesso em: 18 de ago. 2015.

Melo, L. (s.d.). Rato na Coca-Cola nunca existiu, conclui TJ-SP. http://exame.abril.com.br. Acesso em: 17 de ago. 2015.

Pequenas Empresas Grandes Negócios. (s.d.). Como satisfazer um cliente chato e aprender com as críticas dele. Disponível em:

http://revistapegn.globo.com. Acesso em: 18 de ago. 2015.

Procon. (s.d.). Reclamações Fundamentadas 2014. Disponível em: http://sistemas.procon.sp.gov.br. Acesso em: 17 de ago. 2015.

Sebrae.(s.d.). O sucesso nas vendas depende de bom atendimento. Disponível em: www.sebrae.com.br. Acesso em: 20 de ago. 2015.

Silva, L.J.O.L. (2002). Implicações cognitivas e sociais da globalização das redes e serviços telemáticos. Tese de doutoramento. 458p. Departamento de Comunicação e Arte. Universidade de Aveiro- Portugal.

Souza, F. (s.d.). Você Vencedor. A Profecia Auto-realizável. www.vocevencedor.com.br. Acesso em: 17 de ago. 2015.

Vaz, C.A. (2011). Os 8 Ps do marketing digital: o seu guia estratégico de marketing digital. Primeira Edição. São Paulo: Novatec Editora. 